Revista Destaques Acadêmicos, Lajeado, v. 10, n. 1, 2018. ISSN 2176-3070

DOI: http://dx.doi.org/10.22410/issn.2176-3070.v10i1a2018.1703

http://www.univates.br/revistas

\title{
INCLUSÃO DE PESSOAS COM DEFICIÊNCIA INTELECTUAL NO AMBIENTE DE TRABALHO: INFLUÊNCIAS DA APRENDIZAGEM PROFISSIONAL
}

\author{
Tania Maria Schardong ${ }^{1}$, Liciane Diehl ${ }^{2}$
}

Resumo: A inclusão de pessoas com deficiência no ambiente de trabalho tem sido um dos grandes desafios das organizações. Ambientes organizacionais despreparados e a falta de qualificação representam barreiras de acesso ao mercado de trabalho. Este artigo tem como objetivo analisar como a prática da aprendizagem profissional e o acompanhamento influenciam a inclusão das pessoas com deficiência intelectual no ambiente de trabalho de uma cooperativa de produção agropecuária do interior do Rio Grande do Sul (RS). O método de pesquisa seguiu caráter descritivo e abordagem qualitativa, tendo sido utilizadas entrevistas e análise de conteúdo como técnicas de coleta e análise de dados, respectivamente. O estudo permitiu compreender que o curso de aprendizagem profissional tornou-se uma das mais importantes ferramentas de inclusão de pessoas com deficiência intelectual no ambiente de trabalho da organização em questão e forneceu subsídios para que continue desenvolvendo ações voltadas à inclusão de pessoas com deficiência em seus estabelecimentos.

Palavras-chave: Aprendizagem Profissional; Deficiência Intelectual; Inclusão Social.

\section{INTRODUÇÃO}

Com o advento da Lei 8.213, de 24 de julho de 1991, Lei de Benefícios da Previdência Social (LBPS), cria-se, no Brasil, reserva de mercado tanto de pessoas com deficiência, habilitadas, quanto beneficiários da Previdência Social, reabilitados. Embora a legislação brasileira proteja as pessoas com deficiência, ainda existem barreiras e preconceitos a serem superados para que ocorra a integração efetiva ao mercado de trabalho, uma vez que o baixo nível

1 Pós-graduada em Gestão Estratégica de Pessoas (UNIVATES). Graduada em Gestão de Micro e Pequenas Empresas pela (UNIVATES) - E-mail: tania.schardong@gmail.com

2 Doutoranda em Psicologia (UNISINOS) e Mestre em Psicologia Social (PUCRS). Professora e Coordenadora do Curso de Gestão de Recursos Humanos (UNIVATES) - E-mail: licidiehl@gmail.com 
de escolaridade e de qualificação técnica constituem entraves significativos ao processo de inclusão.

A Aprendizagem Profissional estabelece que todas as empresas de médio e grande porte estão obrigadas a contratar, como aprendizes, adolescentes e jovens entre 14 e 24 anos e pessoas com deficiência sem limite máximo de idade. Está prevista na CLT - Consolidação das Leis do Trabalho, na Lei ${ }^{\circ}$. 10.097/2000 e regulamentada pelo Decreto $n^{\circ}$. 5.598/2005 (BRASIL, 2009).

Neste sentido, os cursos de Aprendizagem Profissional podem atuar como facilitadores do processo, à medida que oportunizam o desenvolvimento, a profissionalização e o acesso gradual ao mundo do trabalho. Assim, o artigo ora apresentado assinala como tema de investigação a Aprendizagem Profissional e a inclusão de pessoas com deficiência intelectual no ambiente de trabalho.

O tema em destaque foi norteado pelo seguinte objetivo geral: analisar como a prática da aprendizagem profissional e o acompanhamento influenciam a inclusão das pessoas com deficiência intelectual no ambiente de trabalho de uma cooperativa do agronegócio do interior do Rio Grande do Sul (RS). A fim de apoiar tal objetivo, foram elaborados os seguintes objetivos específicos: (i) definir e compreender a deficiência intelectual e aspectos legais da Aprendizagem Profissional, (ii) apontar os principais aspectos trazidos pela Lei 8.213/9 que estabelece a contratação de pessoas com deficiência nas empresas; (iii) avaliar, a partir da percepção de aprendizes com deficiência intelectual, respectivos genitores, monitores e professores, como ocorre a aprendizagem, o acompanhamento e a inclusão de pessoas com deficiência intelectual no ambiente de trabalho.

A metodologia de pesquisa seguiu caráter descritivo, com abordagem qualitativa. Foram utilizadas entrevistas e análise de conteúdo como técnicas de coleta e análise de dados, respectivamente. A cooperativa em questão foi fundada na década de 1950 e conta com cerca de 2350 cooperados produtores ativos e com quase 3000 colaboradores. Propondo-se a fomentar, captar, industrializar e comercializar a produção de aves, suínos e leite de seus associados, possui 26 unidades de negócio, localizadas em diferentes municípios do RS, e comercializa seus produtos em 23 estados brasileiros e em mais de 50 países. Destaca-se atualmente como uma das maiores cooperativas do agronegócio gaúcho.

\section{REFERENCIAL TEÓRICO}

\subsection{Inclusão social}

Sassaki (2010) conceitua a inclusão social como o processo de adaptação da sociedade à inclusão de pessoas com deficiência em seus sistemas sociais, onde estas se preparam, simultaneamente, para assumir seus papéis na 
sociedade. Ainda segundo o autor, a prática da inclusão social fundamentase em princípios considerados incomuns até então, tais como: "[...] a aceitação das diferenças individuais, a valorização de cada pessoa, a convivência dentro da diversidade humana, a aprendizagem através da cooperação", e permite a construção de uma nova sociedade, não somente de transformações físicas, espaços internos e externos, equipamentos, aparelhos e utensílios, mobiliário, meios de transporte, como também, na mentalidade das pessoas e das próprias pessoas com deficiência (SASSAKI, 2010, p. 40).

A inclusão social, conforme Lima (2006), está relacionada ao sentido de pertencimento, de fazer parte ou de constituir. A autora refere que, apesar de as pessoas serem todas diferentes, cada uma com suas características individuais, todas são iguais como seres humanos, sendo este o aspecto da identidade que indica o pertencimento à espécie. Ainda na visão da autora, a inclusão social "propõe a modificação da sociedade que a torne capaz de acolher todos os tipos de diversidade" (LIMA, 2006, p. 24).

Silva (2013, p. 32) complementa que, "a inclusão social de parcelas marginalizadas da sociedade, ancora-se em princípios de liberdade, igualdade e fraternidade, fazendo parte hoje do próprio conceito de democracia". Fávero (2007, p. 38) contribui referindo que "incluir significa, antes de tudo, deixar de excluir", pressupondo que todos fazem parte de uma mesma comunidade, e que, tanto o Poder Público, quanto a sociedade devem proporcionar as condições necessárias para todos. Ainda na visão da autora, é possível dizer que a Constituição Federal adota princípios apropriados com o movimento de inclusão, pois não somente prevê a adaptação, e sim impõe à República promover e realizar ações que garantam a não-exclusão:

Fica bem claro quando nossa Lei Maior, além de garantir o direito à igualdade, à não discriminação, elege como objetivos fundamentais da República Federativa do Brasil (art. $3^{\circ}$ ): a construção de uma sociedade livre, justa e solidária; garantir o desenvolvimento nacional; reduzir as desigualdades sociais; promover o bem de todos, sem preconceitos (FÁVERO, 2007, p. 38).

Desta forma, os autores defendem que a inclusão social remete ao sentimento de pertencimento do sujeito. Ainda, denota responsabilidade de todos os atores envolvidos: poder público, organizações e sociedade.

\subsection{Deficiência Intelectual}

Deficiência, especialmente quando se refere a seres humanos, não deve ser traduzida como imperfeição ou defeito, já que não existe ser humano totalmente perfeito. Neste caso, a deficiência indica somente limitação ou falta. Sugere que alguém não tem certos atributos físicos, mentais ou sensoriais (auditivas e/ou visuais) encontrados nas demais pessoas (FÁVERO, 2007). 
A Convenção da Guatemala, Decreto número 3956/01, define a deficiência como restrição física, mental ou sensorial, permanente ou transitória, que limita a capacidade de exercer uma ou mais atividades essenciais na vida diária, causada ou agravada pelo ambiente econômico e social (LIMA, 2006).

No que tange a deficiência intelectual, Honora e Frizanco (2008) referem que, é considerada por um ou mais fatores, que venham a causar prejuízo das funções intelectuais e que acompanham o desenvolvimento diferente do cérebro. Observa, ainda, que a deficiência intelectual pode variar de leve a grave, não sendo considerada uma doença ou um transtorno psiquiátrico.

Fávero (2007, p. 32) afirma que:

Deficiência intelectual é o funcionamento intelectual significativamente inferior à média, com manifestação antes dos 18 anos e limitações associadas a duas ou mais áreas de habilidades adaptativas, tais como: comunicação, cuidado pessoal, habilidades sociais, utilização da comunidade, saúde e segurança, habilidades acadêmicas, lazer e trabalho.

Na deficiência intelectual, conforme Fávero (2007), a pessoa carece de instrumentos intelectuais que a impedem de ter total compreensão das coisas, mas que podem ser compensadas, ou pelo menos em parte, com a convivência social e estimulação adequada.

Desta forma, os autores apontam que a deficiência intelectual indica somente uma limitação que reduz a capacidade de total compreensão das coisas, mas que pode ser compensada por meio de outras habilidades e potencialidades.

\subsection{A legislação e os direitos da pessoa com deficiência}

Para Rebelo (2008, p. 45), "a legislação brasileira é uma das mais avançadas no mundo para a proteção e apoio à pessoa com deficiência". Conforme o autor, não é a falta de legislação que impõe lacunas, barreiras e preconceitos em sua aplicação e sim a sua eficácia.

Desde 1949, a legislação federal trata dos direitos das pessoas com deficiência, instituindo selo para obtenção de recursos a hansenianos, campanhas para educação e reabilitação de deficientes visuais, isenções de impostos sobre veículos para paraplégicos ou pessoas com deficiências físicas, pensão especial para pessoas com deficiência física (MARANHÃO, 2005). A autora acrescenta que, a partir de 1989, o Ministério Público passa a ter atribuições específicas para assegurar o pleno exercício dos direitos básicos às pessoas com deficiência, bem como traçar diretrizes para sua formação profissional e inserção no mercado de trabalho público e privado. 
O Estatuto da Criança e do Adolescente, por meio da Lei n. 8.069/90, decreta em seu artigo 54, que é dever do Estado assegurar às crianças e aos adolescentes portadores de deficiência, atendimento educacional e especializado, preferencialmente na rede regular de ensino, assim como, trabalho protegido em seu artigo 66 (MARANHÃO, 2005).

A Constituição Federal também refere que a educação é um direito de todos e obrigação do Estado e da família. Com a colaboração da sociedade, a educação visa ao pleno desenvolvimento do ser humano, preparando-o para o exercício da cidadania e qualificando-o para o mercado de trabalho (HONORA; FRIZANCO, 2008).

Para nortear todo o sistema de proteção institucional da pessoa com deficiência, cria-se, no Brasil, a Lei 7.853/89. A mesma estabelece em seu artigo segundo, que cabe ao poder público e a seus órgãos, assegurar às pessoas com deficiência, o pleno exercício de seus direitos básicos, inclusive educação. A Lei determina ainda, em seu parágrafo único, medidas na área da formação profissional e do trabalho. Neste sentido, surge em $1^{\circ}$ de dezembro de 2005, a Lei da Aprendizagem, regulamentada pelo Decreto $\mathrm{n}^{\circ} 5.598$, que visa à qualificação social e profissional "[...] adequada às demandas e diversidades dos adolescentes, dos jovens, do mundo do trabalho e da sociedade nas dimensões ética, cognitiva, social e cultural do aprendiz" (BRASIL, 2009, texto digital).

Assim como a educação, o trabalho é um dos direitos sociais garantidos pela Constituição Federal. Além de prever os direitos trabalhistas básicos garantidos a todos os trabalhadores, ainda orienta, em seu inciso XXXI, "a proibição de qualquer discriminação no tocante a salário e critérios de admissão do trabalhador com deficiência" (FÁVERO, 2007, p. 121).

Segundo Maranhão (2005, p. 99), a Lei 8.213/91 vem dispor sobre os Planos de Benefícios da Previdência Social, mas em seu artigo 93, prescreve que:

A empresa, com 100 (cem) ou mais empregados, está obrigada a preencher $2 \%$ (dois por cento) a $5 \%$ (cinco por cento) dos seus cargos com beneficiários reabilitados ou pessoas portadoras de deficiência, habilitadas, na seguinte proporção:

I - até 200 empregados - 2\%;

II - de 201 a $500-3 \%$;

III - de 501 a $1000-4 \%$;

IV - de 1.001 em diante $-5 \%$.

Esta reserva de mercado, mais conhecida como sistema de cotas, destinase às pessoas com deficiência habilitadas ou reabilitadas.

Entende-se por pessoa com deficiência habilitada: 
Aquela que concluiu curso de educação profissional de nível básico, técnico ou tecnológico, ou curso superior, com certificação ou diplomação expedida por instituição pública ou privada, legalmente credenciada pelo Ministério da Educação ou órgão equivalente, ou aquela com certificado de conclusão de processo de habilitação ou reabilitação profissional fornecido pelo INSS. Considera-se, também, pessoa portadora de deficiência habilitada, aquela que, não tendo se submetido a processo de habilitação ou reabilitação, esteja capacitada para o exercício da função, conforme estabelece o artigo. 36, $\S \S 2^{\circ}$ e $3^{\circ}$, do Decreto ${ }^{\circ}$ 3.298/99 (BRASIL, 2007, p. 22).

Entende-se por pessoa reabilitada:

Aquela que passou por processo orientado a possibilitar que adquira, a partir da identificação de suas potencialidades laborativas, o nível suficiente de desenvolvimento profissional para reingresso no mercado de trabalho e participação na vida comunitária, conforme estabelece o Decreto número 3.298/99, artigo 31. A reabilitação torna a pessoa novamente capaz de desempenhar suas funções e outras diferentes das que exercia, se estas forem adequadas e compatíveis com sua limitação (BRASIL, 2007, p. 22).

Na visão de Rebelo (2008, p. 49), a Lei 8.213/91 constitui um marco significativo à inclusão de pessoas com deficiência no ambiente de trabalho, pois "prevê a forma de contratação de deficientes e demais mecanismos afetos às necessidades de apoios especiais a cada de deficiência".

Destarte, os autores corroboram que a legislação, seja pela Constituição Federal, Estatuto da Criança e do Adolescente, Lei da Aprendizagem e Planos da Previdência Social, com a reserva de Cotas para pessoas com deficiência, protege as pessoas com deficiência, tanto no que diz respeito ao direito de qualificação profissional, quanto ao direito de acesso ao trabalho.

\subsection{A aprendizagem profissional}

Conforme o Manual da Aprendizagem do Ministério do Trabalho e Emprego (BRASIL, 2009), a aprendizagem cria oportunidades, tanto para o aprendiz, que é preparado para o desempenho de atividades profissionais e capacitado para lidar com diversas situações no mundo do trabalho, como para as empresas, que se beneficiam da qualificação profissional destas pessoas, tão necessária no contexto econômico atual.

O programa de aprendizagem é um programa técnico-profissional fundamentado na execução de atividades teóricas e práticas, sob a orientação de entidade qualificada, público alvo, conteúdos programáticos, período de duração, carga horária teórica e prática, e mecanismos de acompanhamento, avaliação e certificação do aprendizado. As atividades teóricas são aquelas 
desenvolvidas na entidade formadora e sob a orientação desta, e as práticas são as desenvolvidas na empresa (BRASIL, 2009).

A aprendizagem, segundo definição do Estatuto da Criança e do Adolescente, em seu artigo 62, "é a formação técnico-profissional ministrada ao adolescente ou jovem segundo as diretrizes básicas da legislação da educação em vigor, implementada por meio de um contrato de aprendizagem" (BRASIL, 2009, p. 11).

O contrato de aprendizagem é um contrato especial de trabalho, formalizado por escrito e por tempo determinado de, no máximo, dois anos. Deve conter o termo inicial e final, coincidindo com o início e o término do curso de aprendizagem previsto no respectivo programa, bem como o curso, a jornada diária e semanal, a quantidade de aulas teóricas e práticas e a remuneração mensal. Nesse contrato, o empregador assegura ao jovem com idade entre 14 e 24 anos, sem aplicação de limite de idade para pessoas com deficiência, "[...] uma formação técnico-profissional metódica, compatível com o seu desenvolvimento físico, moral e psicológico" (BRASIL, 2009, p. 13).

O empregador tem total liberdade para selecionar o aprendiz, desde que observado o princípio constitucional da igualdade e da vedação a qualquer tipo de discriminação. Deve observar também os dispositivos legais pertinentes à aprendizagem e priorizar a contratação de adolescentes na faixa etária dos 14 aos 18 anos, podendo ainda atingir até o limite máximo de 24 anos. Já para a seleção de pessoas com deficiência, não existe limitador de idade (BRASIL, 2009).

Ouvida a entidade qualificada em formação técnico-profissional metódica, a empresa deve designar formalmente um monitor para cada aprendiz com deficiência. Este monitor coordena os exercícios práticos e acompanha as atividades do aprendiz no estabelecimento, buscando garantir uma formação que possa contribuir para o seu desenvolvimento integral e a consonância com os conteúdos estabelecidos no curso em que foi matriculado (BRASIL, 2009).

\section{MÉTODO DE PESQUISA}

A pesquisa seguiu caráter descritivo e abordagem qualitativa, pois voltou-se para a busca do significado das coisas, ou seja, sobre o que as "coisas" (fenômenos, manifestações, ocorrências, fatos, eventos, vivências, ideias, sentimentos, assuntos) representam para a vida das pessoas (TURATO, 2005).

Os participantes do estudo foram escolhidos por conveniência e contemplaram três aprendizes com deficiência intelectual que realizam a prática da aprendizagem em supermercados da cooperativa; três genitores destes; três monitores, que são funcionários da empresa especialmente treinados para acompanhar os referidos aprendizes em seus ambientes de trabalho; e três professores indicados pela coordenação do curso de Aprendizagem 
Profissional, que os acompanharam durante as aulas teóricas realizadas na entidade formadora, ou seja, na instituição de ensino credenciada para tal finalidade. Os participantes totalizaram, portanto, doze sujeitos.

Os aprendizes com deficiência intelectual, os três genitores destes e os três monitores foram individual e pessoalmente convidados a participar da pesquisa e prontamente manifestaram interesse. Os três professores foram convidados por meio de contato por telefone. A escolha dos aprendizes foi motivada pela diversidade do grau de deficiência que apresentam e pelo local onde trabalham (supermercados). $\mathrm{O}$ varejo tende a empregar e atender pessoas das mais variadas idades e culturas, denotando condições desafiadoras de trabalho. A fim de preservar a identidade dos sujeitos e, ao mesmo tempo, facilitar a identificação dos relatos individuais, os três aprendizes com deficiência intelectual foram nomeados A1, A2 e A3, os três genitores destes foram nomeados G1, G2 e G3, os três monitores, nomeados M1, M2 e M3 e os três professores do curso de Aprendizagem Profissional, nomeados P1, P2, e P3.

A maioria dos participantes é do sexo feminino, sendo dez mulheres e dois homens. A idade média dos aprendizes é de 20 anos, dos genitores, 44 anos, dos monitores, 42 anos e dos professores, 35 anos. Quanto à escolaridade, os aprendizes possuem ensino médio completo, ensino médio incompleto e um, é analfabeto; os genitores possuem quarta série do ensino fundamental, ensino médio completo e ensino superior; dos monitores, dois possuem ensino médio completo e um ensino fundamental completo; e os professores possuem superior completo, pós-graduação e mestrado.

Como técnica de coleta de dados, foram realizadas entrevistas, uma vez que estas favorecem "o acesso direto ou indireto às opiniões, às crenças, aos valores e aos significados que as pessoas atribuem a si, aos outros e ao mundo circundante" (FRASER; GONDIM, 2004, p. 140). Foram elaborados roteiros diferentes conforme o grupo de participantes do estudo: aprendizes, genitores, monitores e professores. As questões eram abertas, de modo que puderam ser acrescentadas algumas perguntas na medida em que ocorreram novos aspectos das entrevistas, cujas informações foram obtidas face a face com os sujeitos de pesquisa.

Para que fosse mantido o sigilo das informações, as entrevistas foram realizadas individualmente, em sala restrita na sede da cooperativa, e foram gravadas com o consentimento dos participantes. Posteriormente, os conteúdos mais significativos das falas foram transcritos para a realização da análise.

Utilizou-se o método de análise de conteúdo conforme Bardin (1977) como a análise das comunicações, que tem como proposta obter, por meio de métodos sistemáticos e objetivos, a captação do conteúdo das mensagens, permitindo a inferência de conhecimentos. Os dados foram categorizados em unidades analíticas apriorísticas, ou seja, a pesquisadora possuía 
antecipadamente, segundo interesses prévios, categorias pré-definidas (CAMPOS, 2004).

\section{RESULTADO E DISCUSSÃO}

O processo de análise das informações obtidas a partir das entrevistas foi organizado em três categorias principais baseadas no objetivo da pesquisa, que foi de analisar como a prática da aprendizagem profissional e o acompanhamento influenciam a inclusão das pessoas com deficiência intelectual no ambiente de trabalho. Assim, as categorias traçadas são: a aprendizagem de pessoas com deficiência intelectual; o acompanhamento de aprendizes com deficiência intelectual no ambiente de trabalho; e a inclusão de aprendizes com deficiência intelectual no ambiente de trabalho.

\subsection{A aprendizagem de pessoas com deficiência intelectual}

As entrevistas com professores do curso Aprendizagem Profissional para pessoas com deficiência intelectual revelaram que a aprendizagem teórica é realizada de maneira a atender as necessidades individuais de cada aprendiz, motivando os mesmos a potencializar suas habilidades e capacidades. Dessa forma, as aulas teóricas seguem conteúdo básico aprovado pelo Ministério da Educação e Cultura e o desenvolvimento das aulas é realizado para que cada aprendiz possa aprender o máximo possível, observando sempre, suas limitações e capacidades. Isso pode ser observado nos relatos dos entrevistados P1 e P2: "[...] a forma de desenvolvimento é diferenciada, realizada com vídeos, jogos, imagens, recortes, colagens. Sempre algo neste sentido, porque só a fala ou a escrita não é o suficiente" (P1);

[...] num primeiro momento, a gente trabalha com situações expositivas, não através de uma leitura, mas sim, através de uma exposição coloquial, de um novo contexto, de um novo cenário ou um novo conteúdo que a gente eventualmente vai trabalhar e logo em seguida, ou ao mesmo tempo, já a ação de alguma situação lúdica ou demonstrativa, para que eles consigam ver e sentir na prática o que está sendo trabalhado, e especialmente, respeitando as capacidades e os limites de cada um (P2).

As expressões dos entrevistados corroboram a reflexão de Fávero (2007), de que a carência de instrumentos intelectuais que impedem as pessoas de ter total compreensão das coisas pode ser compensada com a convivência social e estimulação adequada. Igualmente, a revisão da literatura realizada por Honora e Frizanco (2008) demonstrou que, com a colaboração da sociedade, a educação visa o desenvolvimento do ser humano, qualificando-o para o mercado de trabalho e para o exercício da cidadania. Não obstante, é dever do Estado, assegurar às crianças e aos adolescentes com deficiência, 
atendimento educacional e especializado, bem como, traçar diretrizes para sua formação profissional e inserção no mercado de trabalho público e privado (MARANHÃO, 2005).

As atividades práticas são desenvolvidas em três setores distintos dos supermercados com base nas limitações e nas potencialidades individuais. Os aprendizes aprendem as atividades profissionais, assim como, a lidar com certas situações que acontecem no dia-a-dia no ambiente de trabalho, como refere A1: "[...] ajudo a arrumar os cabides, colocar os cabides no lugar certo, dobrar roupas e levar o lixo. O mais fácil é dobrar as roupas e levar o lixo... o mais difícil é colocar os cabides, é mais complicado" (A1);

$\mathrm{O}$ estímulo e o reconhecimento das potencialidades são demonstradas pelos genitores, monitores e professores, conforme segue: "Ela não tem a visão, falta iniciativa própria muitas vezes. Daí a gente sempre incentiva: 'tu tem que procurar tua monitora e perguntar o que mais tu pode fazer, o que pode ajudar' (G1); "[...] ela sabe fazer as coisas, não tem nada de boba" (M2); e "Tem dias que ela não está muito bem, dai faz algumas coisas erradas, mas dai a gente conversa, tudo tem um jeitinho" (M3); e "Eu acho que estão dispostos a fazer. Se eles vão cumprir as tarefas com 100\% de êxito é outra coisa, mas eles geralmente estão dispostos" (P1).

A cada dia de prática, os aprendizes são desafiados a realizarem atividades com as quais não estavam habituados até então, provocando as mais diversas reações, principalmente, diante das dificuldades. A oportunidade de vivenciar estas dificuldades do dia-a-dia no ambiente de trabalho resultou em crescimento, tanto profissional como pessoal, de cada um dos aprendizes. Deste modo, conforme rege o Manual da Aprendizagem do Ministério do Trabalho em Emprego (BRASIL, 2009), percebe-se que a aprendizagem cria oportunidades para o aprendiz ao passo que é preparado para o desempenho das atividades profissionais, bem como para lidar com as mais diversas situações do mundo do trabalho. As oportunidades ocorrem também para as empresas, pois se beneficiam da qualificação profissional dos aprendizes.

Os genitores referiram que o curso de aprendizagem profissional é uma oportunidade ímpar para a capacitação de jovens portadores de deficiência e sua inserção no mundo do trabalho. Oportunidade esta, que jamais imaginavam que seus filhos pudessem, um dia, ter na vida, como relatam nas falas: "Nós ficávamos nos perguntando o que um dia ela faria na vida, e quando ouvimos no rádio a chamada para o Programa do Jovem Aprendiz para deficientes intelectuais foi como uma luz no fim do túnel" (G1); e

Sempre foi uma preocupação, minha e de meu marido, se nosso filho seria aceito para uma vaga de trabalho, e se as pessoas entenderiam que ele demora um pouco mais que os outros para aprender a fazer as coisas. Então a turma do Jovem Aprendiz veio ao encontro do que nós estávamos precisando naquele momento (G2). 
Portanto, pode-se perceber que a aprendizagem profissional, tanto para os genitores, quanto para os monitores e professores, é uma forma de garantir $\mathrm{o}$ acesso de pessoas com deficiência à qualificação, à prática nas empresas e ao acesso ao mercado de trabalho. Os relatos dos entrevistados vão ao encontro da perspectiva do sentido do trabalho, que está relacionado à inserção na sociedade. De acordo com Tonelli, Morin e Pliopas (2007), o trabalho é uma maneira de pertencer ao conjunto social. A formação profissional, o trabalho exercido, a empresa onde o trabalho é exercido e a própria remuneração são papéis que permitem ao homem interagir com diferentes grupos sociais.

\subsection{O acompanhamento de aprendizes com deficiência intelectual no ambiente de trabalho}

O acompanhamento dos aprendizes com deficiência intelectual durante as atividades práticas na cooperativa é realizado por monitores indicados, que, ao aceitarem o desafio, são treinados pela entidade qualificadora. Assim, aprendem a lidar com as limitações de cada um, assim como a orientar e coordenar as prática da aprendizagem no ambiente de trabalho.

Os aprendizes citaram seus monitores como ponto de referência, tanto para a realização das tarefas, como para esclarecimento de dúvidas, conforme demonstrado nas falas a seguir: "Quando tenho alguma dúvida procuro a monitora" (A3) $e$ "Aprendi com a monitora, gosto muito dela, me dou bem com ela" (A1).

Durante o período de prática na cooperativa, professores da entidade formadora realizam visitas de acompanhamento do aprendiz, cujo objetivo é de coletar informações sobre o desenvolvimento do aprendiz, identificar as principais dificuldades e orientar os monitores quando ocorre alguma dúvida: "Os aprendizes recebem três visitas durante a prática, onde a gente coleta as informações com os monitores" (P1);

A gente faz visitas, observando se eles estão gostando, onde sentem mais dificuldades, onde sentem menos, se eles repassam essas dificuldades aos seus responsáveis. E também conversa com o monitor, para ver como está sendo a experiência de trabalhar com alguém que necessita ser incluído (P2).

Os genitores e os monitores dos aprendizes relataram, também, que houve mudanças significativas em relação ao comportamento e as atitudes de seus filhos após o ingresso no curso de aprendizagem. As falas a seguir representam estes aspectos: "Ela começou a se relacionar mais com as pessoas, está mais feliz e mais disposta." (G1); "[...] ele criou uma autonomia que é incrível. Ele pega o ônibus e vai por tudo." (G2); e "No começo foi complicado, pensei que ela não ia chegar aonde chegou. Hoje ela faz as coisas bem direitinho como se fosse uma pessoa normal." (M3) 
A aprendizagem profissional influenciou, portanto, o comportamento e a autoestima, imprimindo maior autonomia e independência na nova rotina cotidiana de cada um dos jovens aprendizes. As informações coletadas legitimam a premissa de que o trabalho é uma oportunidade que o indivíduo possui de utilizar múltiplas competências (conhecimentos, habilidades e atitudes) e exercer autonomia (pensando e tomando decisões), conforme apontam Silva e Tolfo (2012).

Ainda, as autoras apontam que o trabalho constitui um fenômeno psicossocial fundamental à existência humana e essa condição se explica pelo fato de que, por meio de esforços físicos e psíquicos, os indivíduos mediam as relações com as pessoas com as quais se relacionam. Então, o trabalho se caracteriza como uma categoria central da vida humana.

\subsection{A inclusão de aprendizes com deficiência intelectual no ambiente de trabalho}

A inclusão, conforme Lima (2006), está relacionada ao sentido de pertencimento, de fazer parte ou de constituir, e que, embora sejamos todos diferentes, cada um com suas características individuais, somos todos iguais como seres humanos.

Os relatos dos entrevistados sugerem a importância da valorização de cada pessoa como oportunidade de construção de vínculos, de trabalho em equipe e de um ambiente propício para o bom relacionamento, conforme demonstram as falas: [...] me dou bem com os colegas. Também falo com os demais colegas dos outros setores. Me tratam bem" (A3); "Ele sempre diz 'eu gosto muito de vocês, eu gosto de trabalhar aqui". "Os próprios pais nos dizem que ele se sente muito bem com a gente" (M1); "eu acho que, em relação ao ambiente e de como foram acolhidos, foi muito bom" (P1).

Acredito que o ambiente está sendo muito bom pra ela. As pessoas incentivam e ela fica muito feliz. Poder dizer 'estou trabalhando na Cooperativa X [nome fictício], na loja', pra ela, é um orgulho, é um prazer muito grande de poder falar isso para as pessoas. Então é uma coisa que ela se sente muito bem, e está ajudando muito no crescimento pessoal dela (G1).

As manifestações dos entrevistados quanto ao bom relacionamento dos aprendizes com os colegas, bem como a satisfação destes em realizar a prática da aprendizagem no supermercado, corroboram as reflexões de Sassaki (2010), de que a prática da inclusão social fundamenta-se em princípios como a aceitação das diferenças individuais, a valorização do ser humano, a convivência dentro da diversidade humana e aprendizagem através da cooperação. Ao fomentar o acesso de pessoas com deficiência intelectual à qualificação e ao mundo do 
trabalho, a cooperativa cumpre seu papel de agente transformador, permitindo a construção de uma sociedade livre, justa e solidária (FÁVERO, 2007).

Por meio das entrevistas, pode-se identificar, ainda, que o processo de inclusão é longo, que as dificuldades são reais e cotidianas, mas que a experiência está sendo positiva para todos os envolvidos no processo:

Pra mim, isso foi uma experiência muito boa. A gente sempre pensa que não vai ser capaz de lidar com uma pessoa assim, né? Pelo menos nunca tinha trabalhado com uma pessoa com síndrome de down, e até eu me superei. Eu mesma com os meus limites. A gente tem que ter paciência redobrada. Tem que ter amor, senão não consegue. Mas pra mim é muito gratificante (M3).

O direito de aprender é um direito que eles tem. Nós ficávamos nos perguntando o que um dia ela faria na vida. Nunca imaginávamos que ela viesse a trabalhar e tivesse tanta evolução. Estamos felizes e gratos pela oportunidade que ela está tendo (G1).

A gente parece que coloca eles de lado, mas eles precisam ser integrados. Eles são especiais, tem uma sensibilidade diferente. Eles fazem a gente enxergar as coisas de outra maneira, e isso é bom pra gente. $\mathrm{E}$ eu acho que a sociedade como um todo deveria ter essa oportunidade de conviver com eles para aprender a ter outro olhar (P3).

Ao confrontar o referencial teórico com o resultado do estudo, percebese claramente que a inclusão é um processo de adaptação da sociedade à inclusão de pessoas com deficiência em seus sistemas sociais, que, embora moroso e árduo, adquire visibilidade cada vez maior por meio dos cursos de aprendizagem profissional. Ingressar num curso de aprendizagem profissional, para pessoas com deficiência intelectual, permite às mesmas se prepararem, simultaneamente, para assumir seus papéis na sociedade (SASSAKI, 2010).

\section{CONSIDERAÇÕES FINAIS}

O estudo, cujo objetivo foi analisar como a prática da aprendizagem profissional e o acompanhamento influenciam a inclusão das pessoas com deficiência intelectual no ambiente de trabalho de uma cooperativa de produção agropecuária, contribuiu para compreender que o processo de inclusão ocorre quando os diferentes atores assumem suas responsabilidades. A inclusão de pessoas com deficiência no mercado de trabalho é um expressivo desafio para as organizações e, apesar de existir uma lei que impõe que as empresas, com mais de cem funcionários, contratem pessoas com algum tipo de deficiência, isso não garante a inclusão. 
Neste caso, foram entrevistados os aprendizes, seus genitores, monitores e professores do curso de Aprendizagem Profissional, que demonstraram incentivar e se implicar no processo de inclusão social dos aprendizes com deficiência intelectual na cooperativa. A inclusão vai muito além da contratação e aponta para uma superação de preconceitos e aceitação de limitações e fragilidades do ser humano. Assim, os movimentos a favor da inclusão supõem processos que ocorrem nos níveis social, organizacional, institucional e subjetivo.

No que diz respeito à aprendizagem, percebeu-se, por meio das entrevistas, que o curso Aprendiz Cooperativo para Pessoas com Deficiência está focado em atender as necessidades individuais e potencializar as habilidades e capacidades de cada aprendiz, bem como, em compensar a deficiência intelectual por meio da convivência social e estimulação adequada. Constatou-se, também, que as atividades práticas na cooperativa, oportunizam seu desenvolvimento profissional, moral e psicológico, pois, ao ingressarem no ambiente de trabalho, além de aprenderem um ofício, aprendem também a seguir as normas internas e de convivência com os colegas.

Quanto ao acompanhamento dos aprendizes, verificou-se que é realizado de forma efetiva, por meio de monitores treinados conforme determina a legislação, que coordenam os exercícios práticos e acompanham suas atividades durante os períodos de permanência na cooperativa. Também ocorre por meio de visitas dos professores do curso, que coletam informações sobre o desenvolvimento ou dificuldades encontradas no cotidiano, e orientam tanto os aprendizes quanto os monitores ao restarem dúvidas. Este acompanhamento resulta em vínculos de afetividade, companheirismo e aprendizagem, proporcionando crescimento pessoal e profissional para ambas as partes, conforme demonstrado nas falas.

No que tange à inclusão, constatou-se que o ambiente de trabalho dos supermercados da cooperativa são propícios e adequados para receber, qualificar e fomentar a inclusão de pessoas com deficiência intelectual. As falas recorrentes dos entrevistados evidenciaram a aprendizagem profissional como motivo de orgulho, de sentir-se importante perante a sociedade, como meio de emancipação e de oportunidade ímpar para quem não identifica perspectiva de inclusão social.

Desse modo, esse estudo permitiu uma reflexão sobre a efetiva inclusão e revelou que o curso Aprendiz Cooperativo, nesta organização, tornou-se uma das mais importantes ferramentas de inclusão de pessoas com deficiência intelectual no ambiente de trabalho, e forneceu elementos importantes para que a cooperativa continue desenvolvendo ações voltadas à inclusão de pessoas com deficiência em seus estabelecimentos. Espera-se que o resultado do estudo possa contribuir com maiores subsídios sobre o assunto e também servir como fonte inspiradora para que mais organizações voltem seu olhar para uma 
abordagem verdadeiramente inclusiva e uma oportunidade de crescimento, desenvolvimento e responsabilidade social.

\section{REFERÊNCIAS}

BARDIN, Laurence. Análise de conteúdo. Lisboa: Edições 70, 1977.

BRASIL. Ministério do Trabalho e Emprego. Inclusão de Pessoas com Deficiência no Mercado de Trabalho - SIT. Brasília: MTE, 2007. Disponível em: <http:/ / portal. mte. gov. br/data/files/ FF8080812BCB2790012BCF9D75166284/ inclusao_pessoas_ defi12_07. pdf>. Acesso em: 14 jul. 2014.

. Ministério do Trabalho e Emprego. Manual da aprendizagem: o que e preciso saber para contratar o aprendiz. 2009. Disponível em: <http:/ /www3.mte.gov.br/ politicas _juventude/aprendizagem_apresentacao.asp>. Acesso em: 18 ago. 2014.

CAMPOS, C. J. G. Método de análise de conteúdo: ferramenta para a análise de dados qualitativos no campo da saúde. Revista Brasileira de Enfermagem, Brasília, v. 57, n. 5, p. 611-614, 2004. Disponível em: <http://www.scielo.br/pdf/reben/v57n5/ a19v57n5. pdf>. Acesso em: 13 fev. 2015.

FÁVERO, Eugênia Augusta Gonzaga. Direitos das Pessoas com Deficiência: garantia de igualdade na diversidade. 2. ed. Rio de Janeiro: WVA, 2007.

FRASER, Márcia Tourinho Dantas; GONDIM, Sônia Maria Guedes. Da fala do outro ao texto negociado: discussões sobre a entrevista na pesquisa qualitativa. Paidéia, v. 14, n. 28, p. 139-152, 2004.

HONORA, Márcia; FRIZANCO, Mary Lopes Esteves. Esclarecendo as Deficiências: aspectos teóricos e práticos para contribuir com uma sociedade inclusiva. São Paulo: Ciranda Cultural Editora e Distribuidora Ltda., 2008.

LIMA, Priscila Augusta. Educação Inclusiva e Igualdade Social. São Paulo: Avercamp, 2006.

LOPES, Maura Corcini; FABRIS, Elí Henn (Orgs). Aprendizagem \& inclusão: implicações curriculares. Santa Cruz do Sul: EDUNISC, 2010.

MALHOTRA, Naresh K. Pesquisa de Marketing: foco na decisão. 3. ed. São Paulo: Pearson Prentice Hall, 2011.

MARANHÃO, Rosanne de Oliveira. O Portador de Deficiência e o Direito do Trabalho. São Paulo: LTr, 2005.

MARCONI, Marina de Andrade; LAKATOS, Eva Maria. Fundamentos de Metodologia Científica. 7. ed. São Paulo: Atlas, 2010. 
NASSER, A. C. (Tradução). A pesquisa qualitativa: enfoques epistemológicos e metodológicos. Petrópolis, RJ: Vozes, 2008. Coleção Sociologia.

REBELO, Paulo. A Pessoa com Deficiência e o Trabalho. Rio de Janeiro: Qualimark, 2008.

SASSAKI, Romeu Kazumi. Inclusão: construindo uma sociedade para todos. 8. ed. ampl. rev. Rio de Janeiro: WVA, 2010.

SILVA, Diego Nassif da. Inclusão de Pessoas com Deficiência no Mercado de Trabalho: o Conceito de pessoa com deficiência e sua aplicação jurídica. Curitiba: Juruá, 2013.

SILVA, Narbal; TOLFO, Suzana da Rosa. Trabalho significativo e felicidade humana: explorando aproximações. Revista Psicologia, v. 12, n. 3, p. 341-354, 2012.

TONELLI, Maria José; MORIN, Estelle; PLIOPAS, Ana Lusia Vieira. O Trabalho e Seus Sentidos. Revista Psicologia \& Sociedade, v. 19, 2007.

TURATO, Egberto Ribeiro. Métodos qualitativos e quantitativos na área da saúde: definições, diferenças e seus objetos de pesquisa. Revista Saúde Pública, v. 39, n. 3, p. 507-14, 2005.

VERGARA, Sylvia Constant. Projetos e relatórios de pesquisa em administração. 6. ed. São Paulo: Atlas, 2005. 